\title{
К ВОПРОСУ О СОЗДАНИИ И ВНЕДРЕНИИ ЕДИНОГО ГОСУДАРСТВЕННОГО КАДАСТРА НЕДВИЖИМОСТИ В РЕСПУБЛИКЕ КАЗАХСТАН
}

\section{Елена Валерьевна Медведева}

Восточно-Казахстанский технический университет им. Д. Серикбаева, 070004, Республика Казахстан, г. Усть-Каменогорск, ул. Протозанова, 69, магистр наук, преподаватель школы архитектуры, строительства и дизайна, e-mail: barishnya_ev@mail.ru

\section{Даурен Куттыбаевич Касымов}

Восточно-Казахстанский технический университет им. Д. Серикбаева, 070004, Республика Казахстан, г. Усть-Каменогорск, ул. Протозанова, 69, магистр наук, преподаватель школы архитектуры, строительства и дизайна, e-mail: daur-kas@mail.ru

\section{Азамат Кайсарович Капасов}

Восточно-Казахстанский технический университет им. Д. Серикбаева, 070004, Республика Казахстан, г. Усть-Каменогорск, ул. Протозанова, 69, магистр технических наук, преподаватель школы архитектуры, строительства и дизайна, e-mail: azamat040594@mail.ru

В настоящее время значительное внимание уделяется развитию экономики Республики Казахстан и повышению качества жизни населения, а также созданию условий цифровизации всех сфер деятельности населения. Статья посвящена процессу создания и внедрения единого государственного кадастра недвижимости в Республике Казахстан. Выделены основные цели реализации программы «Цифровой Казахстан», благодаря которой начался процесс создания единого государственного кадастра недвижимости. Произведен анализ ранее существовавших автоматизированных информационных систем ведения государственного земельного кадастра, которые находились в собственности и ведении различных государственных органов. Выделены проблемные вопросы, необходимость внедрения ЕГКН в Республике Казахстан при реализации программы «Цифровой Казахстан». В статье также уделяется внимание к планируемому переходу на новую систему координат к 2022 году, представляющую собой общую земную систему на территорию Казахстана с отчетной основой от центра масс Земли.

Ключевые слова: Цифровой Казахстан, кадастр, автоматизированная информационная система, кадастровый учет, регистрация прав, объект недвижимости, единый государственный кадастр

\section{TO THE QUESTION OF CREATION AND INTRODUCTION THE UNIFIED STATE REAL ESTATE CADASTRE IN THE REPUBLIC OF KAZAKHSTAN}

\section{Yelena $\mathrm{V}$. Medvedeva}

D. Serikbayev East Kazakhstan Technical University, 69, Protozanov St., Ust-Kamenogorsk, 070004, Kazakhstan, M. Sc., Lecturer School of Architecture, Construction and Design, e-mail: barishnya_ev@mail.ru

\section{Dauren K. Kassymov}

D. Serikbayev East Kazakhstan Technical University, 69, Protozanov St., Ust-Kamenogorsk, 070004, Kazakhstan, M. Sc., Lecturer School of Architecture, Construction and Design, e-mail: daur-kas@mail.ru 


\section{Azamat K. Kapasov}

D. Serikbayev East Kazakhstan Technical University, 69, Protozanov St., Ust-Kamenogorsk, 070004, Kazakhstan, M. Sc. in Geodesy, Lecturer School of Architecture, Construction and Design, e-mail: azamat040594@mail.ru

At the moment considerable attention is paid to the development of the economy of the Republic of Kazakhstan and improving the quality of life of the population, as well as creating conditions for digitalization of all spheres of life of the population. The article is devoted to the process of creating and implementing the Unified state real estate cadastre in the Republic of Kazakhstan. The main goals of the Digital Kazakhstan program, which initiated the process of creating a unified state real estate cadastre, are highlighted. The analysis of previously existing automated information systems for maintaining the state land cadastre, which are owned and operated by various state bodies, is carried out. Problematic issues and the need to implement the Unified state real estate cadastre in the Republic of Kazakhstan during the implementation of the "Digital Kazakhstan" program are highlighted. The article also focuses on the planned transition to a new coordinate system by 2022, which is a single earth system on the territory of Kazakhstan with a reporting base from the center of mass of the Earth.

Keywords: Digital Kazakhstan, cadastre, automated information system, cadastre registration, registration of rights, real estate object, unified state cadastre

В настоящее время, одной из важных комплексных программ, которая нацелена на повышение уровня жизни каждого жителя страны, за счет использования и применения цифровых технологий в Республике Казахстан, является государственная программа «Цифровой Казахстан». Основными целями программы является ускорение развития экономики Республики Казахстан и повышение качества жизни населения, а также создание условий для принципиально новой траектории экономики - цифровая экономика будущего.

Программа начала свою реализацию с 2018 года и включает в себя 5 ключевых направлений.

Первое направление называется «Цифровизация отраслей экономики» и включает в себя трансформацию традиционных отраслей экономики с использованием инновационных технологий и возможностей, которые приведут к эффективности работы и повысят рост преобразования средств. Вторым, не маловажным направлением является «Переход на цифровое государство», иначе сказать, реконструкция государственной инфраструктуры для оказания услуг населению и бизнесу, предусматривающая их потребности. Третье направление носит название «Реализация цифрового Шелкового пути» и направлено на обеспечение высокоскоростного и безопасного доступа в интернет, а также на качественное покрытие мобильной связью на всей территории РК. Четвертое направление включает в себя инновации в образовании - формирования новых знаний и компетенций, обеспечение цифровой грамотности жителей страны. Пятое направление называется «Создание инновационной экосистемы» и предусматривает развитие технологического предпринимательства и инновации со стабильными связями между бизнесом, сферой науки и государством [1].

В современном обществе цифровая информация о пространственных данных стала важным стратегическим источником государственного управления и ключом к устойчивому социально-экономическому развитию. В стране 
собрано большое количество данных, полученных в результате производственной деятельности различных предприятий. Но в то же время, большой объем и отсутствие накопленной структуры данных создают информационный барьер и иногда затрудняют процесс обмена информацией. Новые требования рынка к информации в этой области и развитие информационных технологий диктуют необходимость поиска новых решений. Решение, при сложившейся ситуации состоит в организации условий, предоставляющих возможность доступа потребителей к пространственным данным в цифровом виде и их рациональное использование. Согласно проекту национальной инфраструктуры пространственных данных в целях стандартизации, развития и сохранения пространственных данных в актуальном состоянии планируется модернизация государственного геодезического обеспечения Казахстана. К концу 2022 года планируется переход на новую систему координат KAZTRS (Kazakhstan terrestrial reference system), представляющая собой общую земную систему на территорию Казахстана с отчетной основой от центра масс Земли. Данная система в своей основе аналогична системе WGS-84, но имеет уточненные параметры для территории Казахстана [2].

Также планируются работы по объединению отдельных кадастров в единое информационное пространство. В результате реализации программы повысится доступность и улучшится качество предоставляемых населению услуг в сфере земельных отношений, строительства, природопользования, архитектуры, геологии, охраны окружающей среды, а также сельского хозяйства.

Одной из основных тенденций программы является цифровизация земельных отношений, которая входит в состав направления «Переход на цифровое государство». Согласно Постановлению Правительства Республики Казахстан от 12 декабря 2017 года № 827 «Об утверждении Государственной программы «Цифровой Казахстан», данное направление - это открытые прозрачные и удобные возможности для граждан и бизнеса, доступные онлайн и в любое время. Доля государственных услуг, реализованных в электронном формате, повысится до $80 \%$. По принципу модели «Государство - гражданам» будут внедрены цифровые технологии, позволяющие гражданам быстро и самостоятельно получить государственные услуги в электронном виде, формате. Большинство государственных органов, зная о запросах граждан, заранее смогут связываться с ними без необходимости посещения учреждений для оказания услуги, которую выберет гражданин.

Реализация направления будет решена благодаря следующим цифровым решениям:

- Paper-free;

- Электронная биржа труда;

- ИС «Единый госкадастр недвижимости»;

- e-Health [3].

Одним из таких решений затрагивающих и объединяющих услуги в сфере земельных отношений, сельского хозяйства, архитектуры, строительства, природопользования и охраны окружающей среды, а также жилищно-коммунального 
хозяйства является создание и внедрение ИС «Единый госкадастр недвижимости». Любой вновь появившийся объект (дом, дорога) будет отображаться на карте, при условии, что была произведена процедура по оказанию государственных услуг. В результате этого, данные будут обновляться в проактивном режиме.

Реализацией создания единой информационной системы кадастрового учета и регистрации прав на объекты недвижимости занимается государственная корпорации «Правительство для граждан» [4].

Госкорпорация «Правительство для граждан» является единым провайдером государственных услуг.

Согласно Постановлению Правительства Республики Казахстан от 29 января 2016 года №39 «О создании некоммерческого акционерного общества «Государственная корпорация «Правительство для граждан» организация объединила в своей структуре четыре государственных предприятия - «Центр обслуживания населения», «Научно-производственный центр земельного кадастра», «Центр по недвижимости» и «Государственный цент по выплате пенсий» [5].

Над проектом начали работать в 2018 году, на тот момент в Казахстане в сфере недвижимости и земельного кадастра функционировало 4 информационные системы: автоматизированная информационная система государственного земельного кадастра, база данных «Регистр недвижимости», автоматизированная информационная система «Государственный градостроительный кадастр», а также информационная система «Адресный регистр». Они находились в собственности и ведении различных государственных органов, что приводило к дублированию и противоречию информации, неэффективному взаимодействию. Все это значительно увеличивало затраты владельцев при регистрации прав на недвижимость и при получении информации из систем учета. Таким образом, было принято решение о передачи этих информационных систем в доверительное управление в Госкорпорацию «Правительство для граждан» для создания единого государственного кадастра недвижимости (ЕГКН), что позволило обеспечить целостность базы данных, ее полноту, достоверность и оперативное обновление. Кроме того, с появлением единого государственного кадастра недвижимости, будут исключены коррупционные риски.

Сферы обследования и регистрации недвижимости и земли всегда были достаточно инертными в части внедрения новшеств. На тот момент была проведена плодотворная работа по оптимизации государственных услуг в данной области. Реализован пилотный проект по композитному оказанию услуг по определению кадастровой стоимости земельного участка, изменен стандарт государственной услуги «Определение кадастровой (оценочной) стоимости земельного участка». Благодаря этому срок получения документов для земель населенных пунктов сокращен с 10 до 5 рабочих дней. Также граждане имеют возможность одновременно подать заявление на утверждение оценочной стоимости земельного участка, что позволяет им избежать повторного обращения в государственную корпорацию.

В одну электронную услугу «Предоставление сведений из государственного земельного кадастра» были объединены 4 государственные услуги - по предоставлению информации о кадастровой информации, о принадлежности 
земельных участков, об изготовлении идентификационного документа на земельный участок и правоустанавливающего документа первичного предоставления права на земельный участок.

В сентябре 2018 года в Жамбылской, Актюбинской и Северо-Казахстанской областях внедрен пилотный проект по оказанию в электронном формате таких услуг, как изготовление и выдача актов на земельный участок, на право постоянного землепользования, аренды и временного безвозмездного землепользования. Это стало возможным благодаря объединению автоматизированной информационной системы государственного земельного кадастра с интегрированной информационной системой ЦОН [6].

Также существовали проблемные вопросы, которые препятствовали внедрению ЕГКН. Среди них были выделены основные, а именно отсутствие единой системы координат, раздельные организационно-технологические и информационные решения ведения кадастров; отсутствие актуальности и целостности, а также достоверности кадастровых данных, их открытости и полноты; неэффективное взаимодействие информационных систем учета и регистрации, обусловленное организационными и ведомственными ограничениями; отсутствием единых нормативных требований к ведению кадастрового учета, формированию пространственных данных, формата хранения и их точности.

Для решения этих вопросов Некоммерческим акционерным обществом «Государственная корпорация «Правительство для граждан» было предложено министерству сельского хозяйства, совместно с Комитетом национальной безопасности РК, Министерством обороны РК, Министерством цифрового развития, инноваций и аэрокосмической промышленности РК, Министерством юстиции РК, Министерством информации и общественного развития РК проработать вопрос создания единой несекретной системы координат, а местным исполнительным органам определить границы населенных пунктов, особо охраняемых природных территорий, водоохранных полос и зон [7].

Помимо проблемных вопросов, существуют и положительные моменты в создании ЕГКН, которые выделяет государственная корпорация, такие как:

- новая информационная система позволяет достичь прозрачности существующих процессов, так как отсутствие понятной информации, долгие сроки выполнения работ, являются основой для проявлений коррупции;

- автоматизация сбора, обработка, актуализация, хранение и анализ сведений в сфере государственной регистрации;

- учет прав на недвижимое имущество, земельного кадастра базового и региональных уровней;

- ведение единого автоматизированного учета прав на объекты недвижимости.

Не маловажным является и то, что создание ЕГКН способствует облегчению процесса получения услуг в сфере выдачи земель для граждан РК. За счет геопорталов акиматов реализовывается функционал по механизму предоставления земельных участков с объектами недвижимости, где основным модулем системы 
будет общедоступная кадастровая карта. Карта станет информационным источником, позволяющим получить в онлайн режиме сведения для эффективной реализации и обеспечения сделок с недвижимостью и землей, таким образом все сведения будут доступны в базе данных ЕГКН. Данный процесс в дальнейшем будет оптимизирован, что значительно способствует облегчению получения услуг в сфере выдачи земель.

К 2020 году в городах Актобе и Атырау были запущены пилотные проекты по онлайн-предоставлению земельных участков. В последующем реализация онлайн-предоставления земельных участков будет осуществляться и в других крупных городах Казахстана, а именно в городе Алматы и столице республики Нур-Султан.

Комитет по Управлению земельными ресурсами (УЗР) при Министерстве сельского хозяйства РК выделяют основные преимущества внедрения ЕГКН:

- создание единой ИС земельного и правового кадастров;

- создание кадастровой цифровой карты объектов недвижимости;

- переход на ПО с открытым исходным кодом;

- единый электронный архив;

- применение «Block-chain» технологии;

- повышенный уровень общедоступности данных ЕГКН.

В свою очередь, комитет УЗР отмечает следующие серьезные трудности, возникшие при реализации проекта Информационной системы Единого государственного кадастра недвижимости для госкорпорации:

- отсутствие готовых к применению картографических оснований (цифровые карты, генеральных планов, проекты детальной планировки населенных пунктов за исключением городов республиканского значения);

- отсутствие несекретной системы координат (решение вопроса "режим секретности" (ожидается, что только в 2024 году будет реализован проект Национальной инфраструктуры пространственных данных НИПД, который позволит решить вопросы рассекречивания картографических материалов);

- отсутствие инженерно-коммуникационной инфраструктуры на местах (особенно в административных районах, а также данные по инженерным сетям находятся у различных монополистов);

- отсутствие процедуры предоставления земель сельскохозяйственного назначения.

В результате проделанной работы из 15 государственных услуг 11 полностью автоматизированы, три государственные услуги частично автоматизированы. Вместе с тем, в данном направлении продолжается работа по цифровизации всех государственных услуг. Разработка информационной системы Единого государственного кадастра недвижимости направлена на совершенствование системы кадастрового учета и регистрации прав (обременений) на объекты недвижимости, с учетом оптимизации и автоматизации государственных услуг. Реализация проекта позволит достичь прозрачности существующих процессов, 
исключить дублирование, оптимизировать бизнес-процессы, связанные с оформлением недвижимости и земельных участков [8].

В заключении необходимо отметить, что реализация создания и внедрения единого государственного кадастра недвижимости не стоит на месте, а продолжает свою работу по улучшению услуг в сфере земельных отношений, на территории всей Республики. На сегодняшний день по данным, приведенным на официальном сайте «Цифровой Казахстан» во вкладке «Проекты и результаты» можно наблюдать актуальные процентные данные по реализации проекта (рисунок) [9].

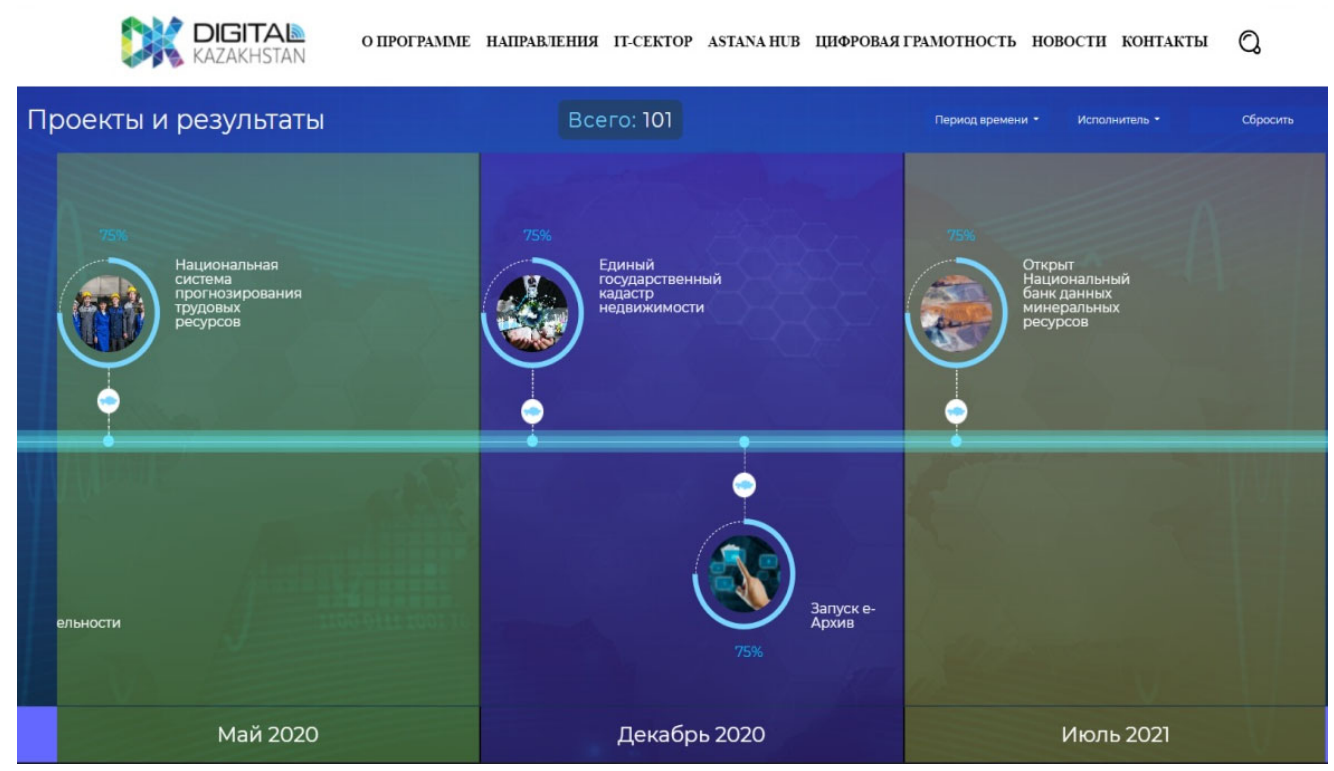

Рис. Данные «Проекты и результаты» предоставленные с официального сайта «Цифровой Казахстан»

Начиная с 2018 года, по состоянию на декабрь 2020 года проект реализован на 75\%. В плане мероприятий по реализации Государственной программы «Цифровой Казахстан» срок исполнения создания ЕГКН указан на декабрь 2021 года. На данный момент продолжаются работы по необходимости интегрирования геопорталов акиматов с единой системой государственной кадастра. По поручению министра цифрового развития, инноваций и аэрокосмической промышленности планируется запуск услуги, онлайн предоставления земельных участков во всех регионах страны до 31 декабря 2020 года [10].

\section{БИБЛИОГРАФИЧЕСКИЙ СПИСОК}

1. № 827 «Об утверждении Государственной программы «Цифровой Казахстан» [Электронный pecypc]. - Режим доступа: https://adilet.zan.kz/rus/docs/P1700000827 (дата обращения 05.11.2020).

2. Сериков Д. К 2022 году Казахстан перейдет на новую систему координат [Электронный ресурс]. - Режим доступа: https://inbusiness.kz/ru/news/k-2022-godu-kazahstan-perejdet-nanovuyu-sistemu-koordinat (дата обращения 05.11.2020). 
3. Официальный интернет-ресурс Государственной программы «Цифровой Казахстан» Переход на цифровое государство [Электронный ресурс]. - Режим доступа https://digitalkz.kz/perechod-na-cifrovoe-gosudarstvo/ (дата обращения 05.11.2020).

4. Официальный интернет-ресурс НАО «ГОСУДАРСТВЕННАЯ КОРПОРАЦИЯ «ПРАВИТЕЛЬСТВО ДЛЯ ГРАЖДАН» Стратегия развития некоммерческого акционерного общества «Государственная корпорация «Правительство для граждан» на 2018 - 2022 гг. [Электронный ресурс]. - Режим доступа: https://gov4c.kz/about/strategiya/ (дата обращения 05.11.2020).

5. Постановление Правительства Республики Казахстан от 29 января 2016 года № 39 О создании некоммерческого акционерного общества «Государственная корпорация «Правительство для граждан» [Электронный ресурс]. - Режим доступа: http://adilet.zan.kz/rus/docs/P1600000039 (дата обращения 05.11.2020).

6. Иванова Е. От принципа «одного окна» к принципу «одного заявления»: АО «Республиканская газета «Казахстанская правда» [Электронный ресурс]. - Режим доступа: https://www.kazpravda.kz/articles/view/ot-printsipa-odnogo-okna-k-printsipu-odnogo-zayavleniya/ (дата обращения 05.11.2020).

7. Ковалева Т. Внедрить единую систему кадастрового учета предложил «Правительство для граждан» [Электронный ресурс]. - Режим доступа: https://www.zakon.kz/4891514-vnedritedinuyu-sistemu-kadastrovogo.html (дата обращения 05.11.2020).

8. «Это не фантастика». Чем хорош для казахстанцев Единый госкадастр недвижимости [Электронный ресурс]. - Режим доступа: http://today.kz/news/kazahstan/2020-03-14/793690-etone-fantastika-chem-horosh-dlya-kazahstantsev-edinyij-goskadastr-nedvizhimosti/ (дата обращения 05.11.2020).

9. Официальный интернет-ресурс Государственной программы «Цифровой Казахстан» Проекты и результаты [Электронный ресурс]. - Режим доступа: https:/digitalkz.kz/projects/ (дата обращения 05.11.2020).

10. Онлайн выдачу земли введут в Казахстане [Электронный ресурс]. - Режим доступа: http://today.kz/news/progress/2020-02-04/791409-onlajn-vyidachu-zemli-vvedut-v-kazahstane/ (дата обращения 05.11.2020).

(C) E. В. Медведева, Д. К. Касымов, А. К. Капасов, 2021 